\title{
Atividade diária da abelha Jataí em uma fazenda de produção orgânica
}

\author{
Maiara de Jesus Lima'; Miriam Gimenes ${ }^{2}$ \\ Maiara de Jesus Lima PROBIC/UEFS, Graduando em Agronomia, Universidade \\ Estadual de Feira de Santana, e-mail: maiaralima19@gmail.com \\ Miriam Gimenes, DCBio, Universidade Estadual de Feira de Santana, e-mail: \\ miriagimenes@gmail.com.
}

Palavras-Chave: Abelhas; Atividade diária; Meliponinae.

\section{INTRODUÇÃO}

Os meliponíneos possuem mais de 300 espécies conhecidas em todo o mundo caracterizando-se basicamente por serem sociais e possuírem o ferrão atrofiado. Essas abelhas estão entre os principais responsáveis pela polinização da grande maioria das espécies vegetais do nosso país (Freitas, 2003). Muitas espécies de abelhas sem ferrão produtoras de mel são criadas artesanalmente (meliponicultura), principalmente por comunidades tradicionais e povos indígenas do Brasil, por isso, são também denominadas de "abelhas indígenas" (GOUW, 2011).

A atividade externa das abelhas basea-se no momento de entrada e saída destas da colônia, com ou sem material, durante um determinado tempo. Tais atividades estão relacionadas a uma série de comportamentos, como coleta de material para nidificação, higiene e coleta de alimentos. Assim, é comum observar abelhas ao longo do dia entrando na colônia com pólen, ou saindo da mesma com detritos (Silva 2012).

O projeto teve como objetivo analisar a atividade diária de abelhas da espécie (Tetragonisca angustula) em uma área de produção orgânica, observando o comportamento delas com referência aos horários de forrageamento. Foi observada a entrada e a saída das abelhas, registrando o que estão transportando para colônia e o que estão retirando. A importância de observar a entrada e saída das abelhas é que possibilita a relação com o horário de abertura das flores. A partir disso é possivel escolher uma espécie de abelha adequada para polinização de uma plantação. A maioria das plantas tem a abertura da flor no inicio da manhã, o que pode coincidir com o horário de coleta de pólen das abelhas. Os recursos florais influenciam de forma positiva na atividade de voo (Gouw, M. Sian, 2011).

\section{MATERIAL E MÉTODOS}

O projeto foi realizado na Chácara Bocaiúva (23,5 hectares) localizada no Distrito de Humildes (Feira de Santana - BA). A propriedade é certificada para a produção e comercialização hortifrutícola orgânica. A chácara faz parte do Cadastro Nacional de Produtores Orgânicos do Ministério da Agricultura e, além do selo unificado, a empresa possui o selo do IBD (Instituto Biodinâmico). A Chácara Bocaiúva 
desenvolve um projeto de reflorestamento promovendo o equilíbrio ecológico, preservando e recuperando espécies nativas.

Foram observadas três colônias de meliponíneos da espécie Tetragonisca angustula. As observações foram feitas bimestralmente (mês sim, mês não), durante três dias, das 7:00 ás 16:00h, no período de agosto de 2015 a agosto 2016. No período de uma hora cada colônia era observada por 15 minutos. Foram feitos registros do número de abelhas que saiam e entravam na colônia, entrada com pólen e a saída com resíduos. Os dados macroclimáticos dos diferentes meses foi obtido através da estação meteorológica da UEFS.

\section{RESULTADOS}

Durante a analise da atividade externa das três caixas de meliponíneos a temperatura diária variou de $22^{\circ} \mathrm{C}$ (às $15: 00 \mathrm{~h}$ em 30/10/2015) à $35^{\circ} \mathrm{C}$ (ás 13:00 em $10 / 12 / 2015)$. Os valores mais altos acima de $30^{\circ} \mathrm{C}$ foram obtidos no intervalo de hora entre 11:00 e 15:00 h. A umidade relativa variou de 34\% a 75\%.

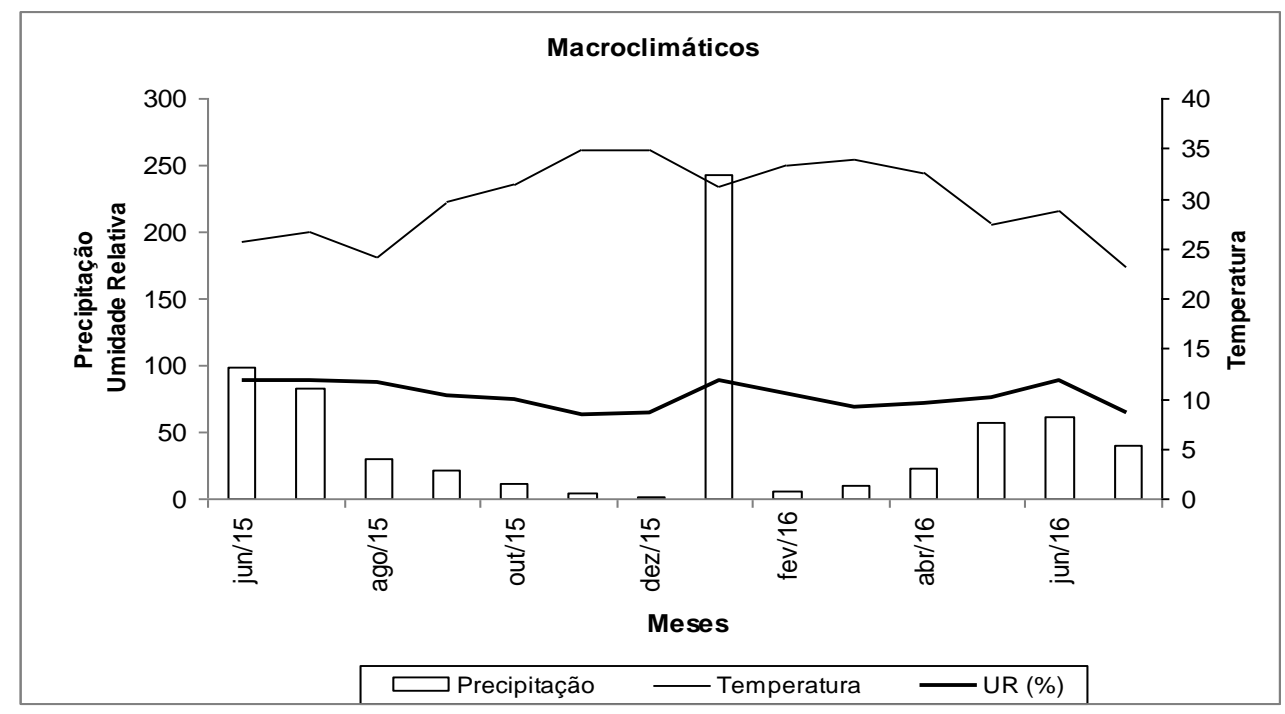

O maior número de entrada com pólen ocorreu no mês de abril/16 para todas as caixas já o menor número variou. Na caixa um, ocorreu no mês de outubro/16, nas caixas dois e três foram no mês de junho/16. O maior número de saída com lixo ocorreu no mês de fevereiro/16 e o menor número no mês de abril para todas as caixas. Indicando desta forma que as caixas estavam em fase de provisionamento das células no mês de abril.

Levando-se em consideração o número semelhante de atividade das 3 colônias de abelhas, podemos sugerir que estas estariam no mesmo nível de desenvolvimento, mas fica difícil avaliar se estas colônias seriam fortes ou fracas. Também temos que considerar que as caixas 2 e 3 não foram observadas nos meses de outubro e dezembro/15, onde provavelmente seria encontrado um maior número de atividade de voo. (Tabela 1). 
Tabela 1. Quantidade de abelhas entrando e saindo no ninho, entrando com pólen e saindo com lixo referente aos meses nas três colônias de Tetragonisca angustula, observada.

\begin{tabular}{cccccccccc}
\hline Meses & $\begin{array}{c}\text { Caixa 1 } \\
\text { Ent+Saída }\end{array}$ & $\begin{array}{c}\text { Caixa 1 } \\
\text { Pólen }\end{array}$ & $\begin{array}{c}\text { Caixa 1 } \\
\text { Lixo }\end{array}$ & $\begin{array}{c}\text { Caixa 2 } \\
\text { Ent+Saída }\end{array}$ & $\begin{array}{c}\text { Caixa 2 } \\
\text { Pólen }\end{array}$ & $\begin{array}{c}\text { Caixa 2 } \\
\text { Lixo }\end{array}$ & $\begin{array}{c}\text { Caixa 3 } \\
\text { Ent+Saída }\end{array}$ & $\begin{array}{c}\text { Caixa 3 } \\
\text { Pólen }\end{array}$ & $\begin{array}{c}\text { Caixa 3 } \\
\text { Lixo }\end{array}$ \\
out/15 & 3599 & 53 & 117 & 0 & 0 & 0 & 0 & 0 & 0 \\
dez/15 & 2832 & 82 & 123 & 0 & 0 & 0 & 0 & 0 & 0 \\
fev/16 & 2756 & 137 & 183 & 2671 & 151 & 177 & 3054 & 164 & 236 \\
abr/16 & 2853 & 178 & 114 & 2827 & 243 & 113 & 2699 & 201 & 141 \\
jun/16 & 2703 & 152 & 151 & 3211 & 147 & 123 & 3014 & 162 & 142 \\
\hline
\end{tabular}

Quando começava a observação dos ninhos, às 7:00 h, as abelhas já tinham dado inicio as atividades porque já tinham abelhas retornando do campo com pólen na corbícula.

Durante os meses de outubro, dezembro e abril as abelhas da Caixa 1 apresentaram atividade diária para coleta de pólen de forma homogênea durante o tempo de observação (das 7:00 às 16:00 h), não apresentando um pico de atividade marcado. Durante este período a temperatura variou de 25 a $29^{\circ} \mathrm{C}$. Nas caixas 2 e 3, durante o mês de abril, foram observadas atividades mais intensas até às 12:00 h (intervalo das 11:00 às 12:00 h). Para as 3 caixas nos meses de fevereiro e junho/16 foi observada uma variação nas atividades diárias, sendo a mais baixa no intervalo das 7:00 às 8:00 h, aumentando ao longo do dia.

O horário de atividade de coleta de pólen, verificado através das entradas das abelhas com pólen na corbícula, pode estar relacionado com o horário da oferta de pólen pelas flores, que ocorre geralmente de manhã (Gouw, 2011). Porém, neste estudo este fato não foi observado de forma nítida, tendo em vista a pequena diferença dos horários de entrada com pólen no ninho durante os meses de estudo nas 3 caixas de abelhas. Talvez, uma explicação para isso seja o fato da área de estudo ser de produção agrícola com plantas selecionadas e não uma área com vegetação natural.

Foi visto na literatura que Melipona rufiventris apresentou aumento na atividade a partir das 15:00 com pico às 17:00 h. Já Melipona asilvai apresentou maior atividade pela manhã, praticamente cessando à tarde. Algumas pesquisas mostram que essas diferenças no horário de pico de atividade são comuns entre as espécies de abelhas e tem relação com o horário de fornecimento de recursos e a preferência de cada espécie pelos mesmos (Pereira et al., 2007). Nas caixas observadas os horários em que se registrou o maior número de atividades de saída e entrada de abelhas foram entre 11:00 e 15:00 h, nestes horários o valor de temperatura estava elevada, sendo a média entre 29 e $30^{\circ} \mathrm{C}$. 


\section{CONCLUSÕES}

As abelhas das caixas observadas não apresentaram ritmo, nem pico de atividades nas horas em que foram avaliadas.

O mês de abril foi o mês mais favorável a todas as caixas para coleta de pólen.

\section{REFERÊNCIAS}

GOUW, M. SIAN. Ritmos de atividade diária de vôo de abelhas da subtribo Meliponina em colônias de criação no Povoado de Pedra Branca, Santa Teresinha (BA). Tese (Mestrado em Zoologia)- Universidade Estadual de Feira de Santana, Feira de Santana, Bahia, 2011.

MAIA-SILVA.C et al. Guia de plantas visitadas por abelhas na caatinga. Fortaleza, Ed. Fundação Brasil Cidadão 99p. 2012.

NOGUEIRA-NETO,P. A vida e criação de abelhas indígenas sem ferrão. São Paulo: Nogueirapis, 1997.445 p.

RECH, A. R et al. Biologia da polinização. Rio de Janeiro, Ed. Projeto Cultura. 2014.

SILVA, C. I et al. Guia ilustrado de abelhas polinizadoras no Brasil. São Paulo, 2014.

SILVA, W. P.; PAZ, L. R. J. Abelhas sem ferrão: muito mais do que uma importância econômica. Bahia, 2012.

SILVA, W. P. (APOIDEA, APIDAE) e a influencia dos fatores ambientais e meteorológicos, em uma área da chapada Diamantina, Bahia. Tese (Mestrado em Zoologia)- Universidade Estadual de Feira de Santana, Feira de Santana, Bahia, 2012.

SILVA, W.P. 2012. Ritmo diário das atividades externas de Nannotrigona testaceicornis (Lepetier, 1836)

SEELEY, THOMAS D. . Ecologia das abelhas. Porto Alegre, Ed. Paixão Editores 256p. 2006.

PEREIRA, F. M et al.,2006 . Atividade de vôo de espécies demelipona

(Hymenoptera, Apidae) nas condicões de Teresina, PI. PIAUI. EMBRAPA. 21p.

VENTURIERI, G. C. . Criação de abelhas indígenas sem ferrão. Bélem, Embrapa 55p. 2008.

VILLAS-BÔAS, J. Manual tecnológico mel de abelhas sem ferrão. Brasilia, 100p. 2012.

WOLFF, L. F et al. Localização do apiário e instalação das colmeias. Teresina, Embrapa 30p. 2006. 